Publicado en Internet:
28-octubre-2015
Ramona Martín Martín:
rmartin@grupsagessa.com

Palabras clave:

- Miositis osificante

- Traumatismo

\title{
Miositis osificante traumática: a propósito de un caso
}

\author{
R. Martín Martín
}

Médico adjunto. CAP Marià Fortuny. Reus, Tarragona. España.

\begin{abstract}
ป La miositis osificante traumática es una patología infrecuente de etiopatogenia incierta, aunque actualmente se acepta que se produce por metaplasia de las células mesenquimales del tejido conectivo. Suele afectar a adolescentes y adultos jóvenes, generalmente como consecuencia de un traumatismo sobre una zona muscular; en el $80 \%$ de los casos se localiza en las extremidades inferiores. La clínica aparece dos o tres semanas después del traumatismo, aunque la mayoría de pacientes no recuerda el evento causal. Para el diagnóstico se puede requerir radiografía simple, ecografía, tomografía axial computarizada o resonancia magnética, que a veces no pueden distinguir esta patología de otras lesiones malignas como sarcomas de partes blandas u osteosarcomas. Por ello, para el diagnóstico de certeza, con frecuencia se requiere biopsia. El tratamiento generalmente es conservador. La cirugía solo se realiza en casos seleccionados por el riesgo de recidiva.
\end{abstract}

\section{Traumatic myositis ossificans: case report}

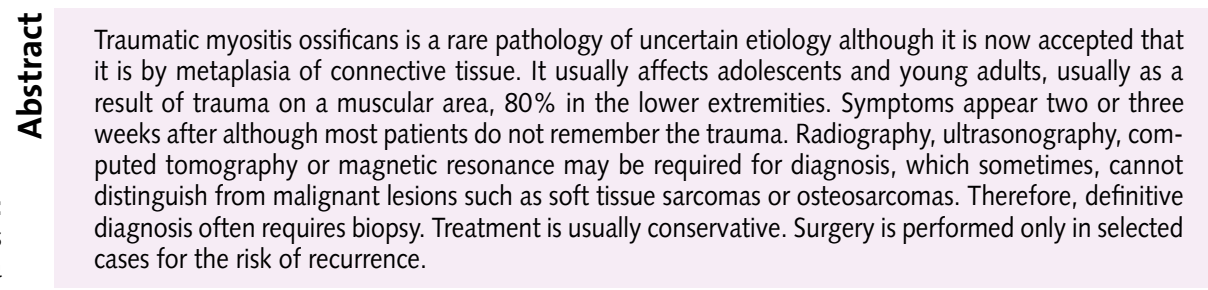

\section{INTRODUCCIÓN}

La miositis osificante traumática es una patología infrecuente. Suele afectar a adolescentes y adultos jóvenes, generalmente, como consecuencia de un traumatismo sobre una zona muscular. Aunque la etiopatogenia es aún incierta, lo más aceptado actualmente es la presencia de metaplasia de las células mesenquimales indiferenciadas del tejido conectivo inducida por el traumatismo, y probablemente participan proteínas osteogénicas ${ }^{1}$.

En la exploración física destaca la presencia de una tumoración dura indistinguible de otras lesiones tumorales. El antecedente traumático y los signos locales inflamatorios al inicio del cuadro son los datos clínicos que pueden orientarnos. Sin embargo, cuando el traumatismo no es claro, la sospecha clínica es difícil, sobre todo porque tras unos días

Cómo citar este artículo: Martín Martín R. Miositis osificante traumática: a propósito de un caso. Rev Pediatr Aten Primaria. 2015;17:347-50. 
cede la clínica local y persiste la tumoración de aspecto maligno. Por ello suelen diagnosticarse inicialmente como procesos malignos, principalmente sarcomas de partes blandas, aunque también puede simular focos de osteomielitis u osteosarcomas $^{2-5}$.

\section{CASO CLÍNICO}

Niña de diez años, sin antecedentes de interés, que, sin recordar traumatismo previo, consulta refiriendo una tumoración dolorosa en el muslo izquierdo advertida dos días antes. No presenta fiebre, pérdida de peso ni otra sintomatología. En la exploración física se palpa una tumoración dolorosa de $7 \times 11 \mathrm{~cm}$ en el tercio medio-distal del muslo izquierdo. La extremidad está mínimamente aumentada de tamaño respecto a la contralateral. La piel presenta coloración y temperatura normales. El resto de la exploración física es normal.

Ante los hallazgos clínicos se solicita radiografía simple del fémur izquierdo (Fig. 1) que evidencia una masa calcificada. Posteriormente se solicita ecografía del muslo (Fig. 2), que pone de manifiesto una imagen oval con múltiples imágenes hiperecogénicas en su interior que provocan sombras acústicas posteriores, lo que no sugiere un diagnóstico definitivo. Para concretar el diagnóstico se solicita una tomografía computarizada (TC) (Fig. 3), que pone de manifiesto una masa calcificada que no engloba estructuras neuromusculares, de características aparentemente benignas, pero que no permite descartar que se trate de un condroma de partes blandas.

Ante la posibilidad de patología maligna, se deriva a un hospital de tercer nivel para su valoración, donde se reevalúa el caso. Un familiar recuerda un traumatismo con el manillar de la bicicleta unos cuatro meses antes de la consulta inicial, seguido de dolor e inflamación los siete días posteriores. EI caso se orienta inicialmente como un hematoma calcificado y se sugiere un tratamiento conservador y una visita de seguimiento tres meses después. Pasado ese tiempo, solicitan una radiografía
Figura 1. Radiografía simple. Muestra una masa calcificada en la región distal del fémur, sin contacto con el córtex óseo

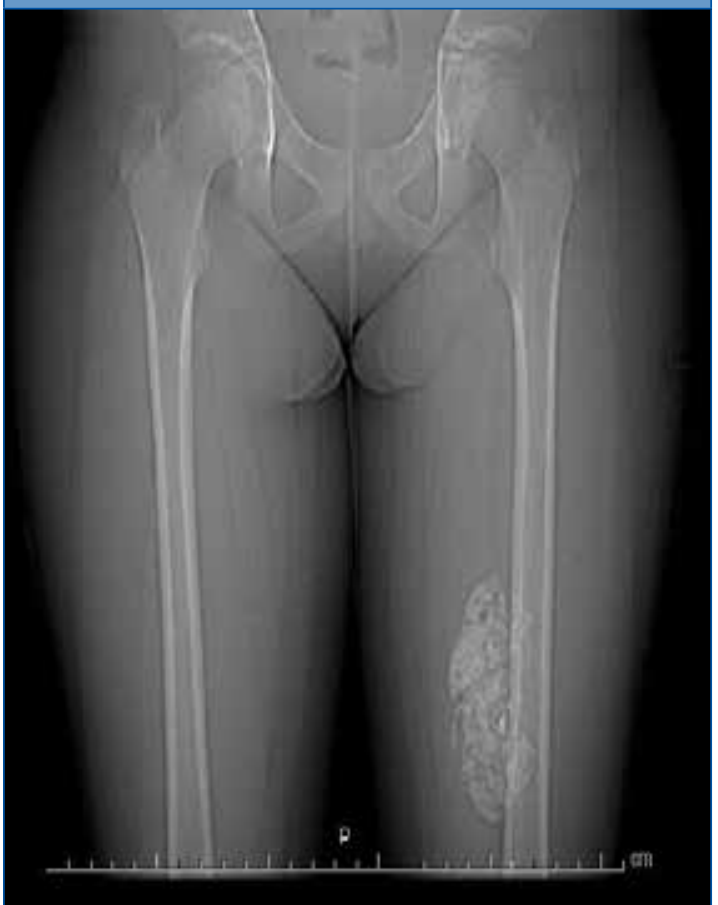

Figura 2. Ecografía de partes blandas. Imagen ovalada de $7,5 \times 5 \mathrm{~cm}$ con múltiples imágenes

hiperecogénicas que causan sombra acústica posterior. Provoca el desplazamiento de planos musculares adyacentes sin invasión de los mismos

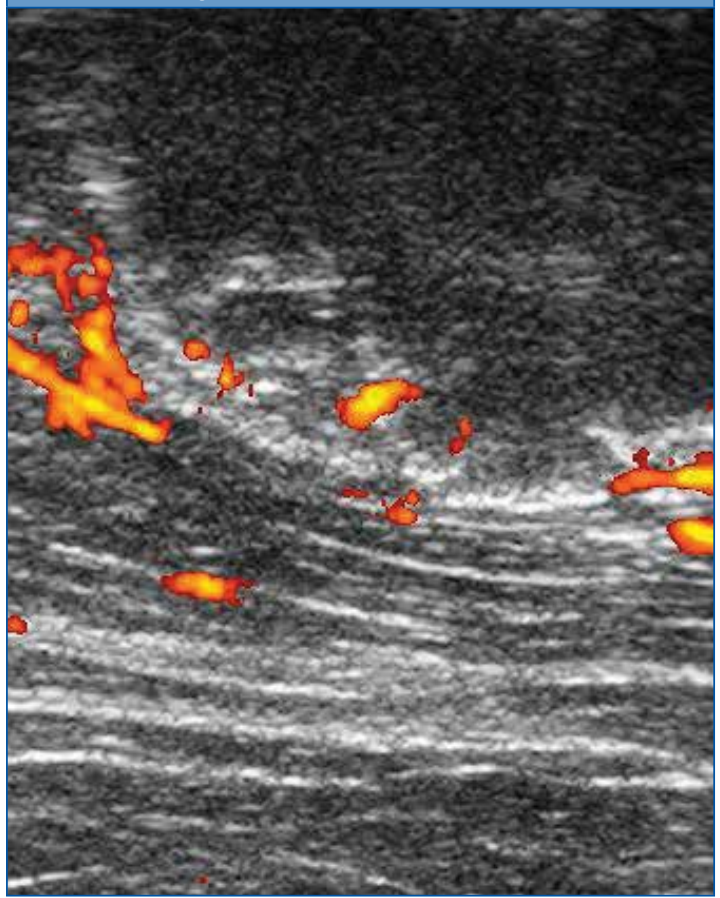




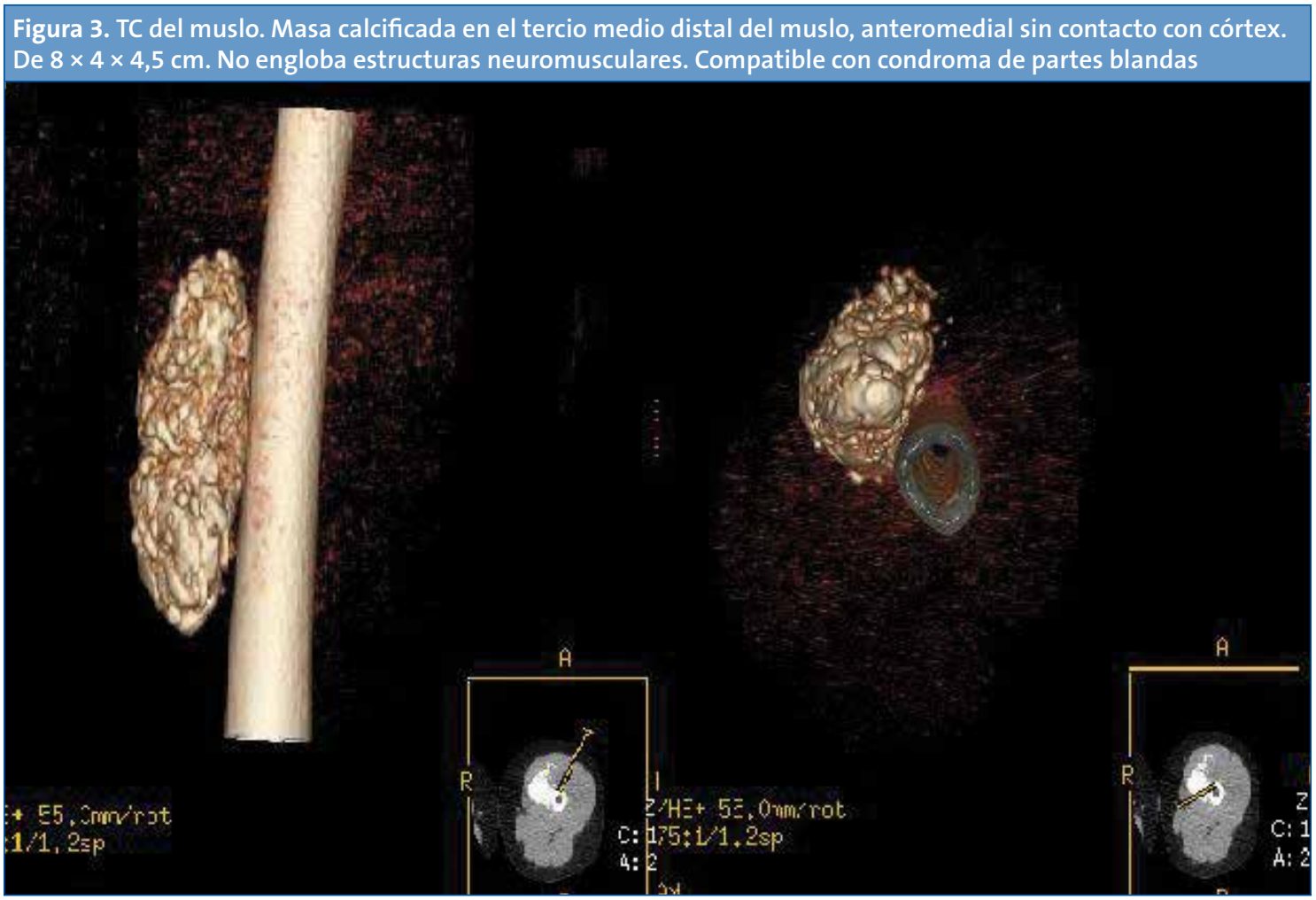

simple de control que no muestra cambios respecto a la previa. Ante la evolución clínica, revaloran la TC inicial y reorientan el diagnóstico como miositis osificante traumática (MOT). Cuatro años después la lesión apenas ha disminuido su tamaño, pero la cirugía no se plantea ya que clínicamente la paciente está asintomática.

\section{DISCUSIÓN}

Samuelson y Coleman ${ }^{4}$ dividen la miositis osificante en cuatro grupos distintos: 1) miositis osificante progresiva o fibrodisplasia de herencia autosómica dominante; 2 ) miositis osificante asociada a enfermedad crónica; 3) miositis osificante traumática, y 4) miositis osificante pseudomaligna (no traumática), cuyo diagnóstico diferencial es con el osteosarcoma extraóseo.

En la miositis osificante traumática la edad de máxima incidencia es durante la segunda y tercera décadas de la vida. Generalmente se localiza en las extremidades (el 80\% de los casos en las inferiores), con preferencia por los músculos cuádriceps, braquial anterior y músculos de la mano, pero puede encontrarse en las fascias, tendones y tejido subcutáneo. La población de mayor riesgo son los deportistas.

La clínica se presenta dos o tres semanas después de un traumatismo -aunque la mayoría de los pacientes no recuerda el hecho concreto-con edema, induración y formación de una masa firme y pétrea, poco dolorosa y expansiva. La extremidad puede aumentar su tamaño, ser dolorosa a la movilización y presentar diferentes grados de impotencia funcional. La piel puede estar caliente.

Existen dos tipos: MOT por único traumatismo importante (como nuestro caso) y MOT circunscrita por pequeños traumatismos recidivantes.

La radiografía simple suele ser normal al inicio del cuadro y posteriormente puede mostrar una radiodensidad débil, irregular y flocular. Cuando la lesión madura (2-4 semanas), la apariencia radiográfica cambia según aumenta la formación de hueso, empezando la calcificación por la periferia con centro 
radiolucente (el osteosarcoma calcifica del centro a la periferia). En la mayoría de los pacientes, la lesión no se pega al hueso subyacente, pero puede hacerlo si descansa cerca del hueso y la lesión original indujo una reacción del periostio adyacente. La radiografía simple es poco útil para el diagnóstico inicial, aunque sí lo es para el seguimiento, pues nos permite ir valorando la evolución de las calcificaciones.

La ecografía es una técnica de imagen inocua y útil para valorar lesiones de partes blandas, aunque depende mucho de la experiencia del explorador. Las imágenes que aporta indican con frecuencia infiltración de la grasa subcutánea y del músculo, lo cual sugiere malignidad. El osteosarcoma en fase inicial es difícil diferenciarlo de la miositis, pero las líneas hiperecogénicas con sombra acústica posterior sugieren MOT aunque estas no aparecen hasta las 2-3 semanas de evolución.

La TC y la resonancia magnética (RM) muestran, con mayor resolución que la ecografía, las relaciones de la tumoración y la infiltración de estructuras vecinas. Pero algunos patrones pueden hacerla indistinguible de sarcomas de partes blandas $u$ osteosarcomas.

Las técnicas de imagen pueden llevarnos a confusión y no es infrecuente que el diagnóstico definitivo requiera una biopsia de la lesión para descartar malignidad. Macroscópicamente, la miositis osificante tiene estructura similar a un huevo, con una cáscara dura en la periferia y un centro blando. La masa puede unirse al hueso por un tallo o podría estar en continuidad con el periostio. Microscópicamente, en la fase aguda hay una proliferación de

\section{BIBLIOGRAFÍA}

1. Micheli A, Trapani S, Brizzi I, Campanacci D, Resti M, de Martino M. Myositis ossificans circumscripta: a paediatric case and review of the literature. Eur J Pediatr. 2009;168:523-9.

2. Alonso Calderón JL, Delgado Valdueza J, Deprada Vicente I. Miositis osificante circunscrita axilar. An Pediatr (Barc). 2004;60:373-5. células mesenquimales indiferenciadas que infiltran el músculo. Aproximadamente a las 2-3 semanas empieza la producción de osteoide en la periferia y el tejido fibroso empieza a formarse en la cáscara. El centro de la lesión será una masa irregular de fibroblastos inmaduros. Siguiendo hacia la periferia, habrá islas de osteoide desorganizado. En el borde de la lesión hay trabéculas de tejido lamelar óseo. Puede haber también un componente de cartílago. En esto se diferencia del osteosarcoma, que suele mostrar uniformidad en el aspecto histológico en toda su extensión o iniciar osificación del centro hacia la periferia.

El diagnóstico diferencial cabe hacerlo con el hematoma calcificado (depósito de calcio en el músculo, a diferencia de la MOT, que es formación de hueso nuevo), sarcomas de partes blandas y el osteosarcoma.

El tratamiento es generalmente conservador. La cirugía en fases precoces está contraindicada ya que el riesgo de recidiva es alto. La exéresis es una opción después de que haya una disminución de la actividad ósea. Si se deja, la masa puede disminuir de tamaño espontáneamente.

\section{CONFLICTO DE INTERESES}

La autora declara no presentar conflictos de intereses en relación con la preparación y publicación de este artículo.

\section{ABREVIATURAS}

MOT: miositis osificante traumática • RM: resonancia magnética • TC: tomografía computarizada.

3. Azagra de Miguel A, Carro Alonso B, Fernández Gómez JA y Villavieja Atance JL. Miositis osificante circunscrita. An Pediatr (Barc). 2011;74:338-9.

4. Samuelson KM, Coleman SS. Nontraumatic myiositis ossificans in healthy individuals. JAMA. 1976;235: 1132-3.

5. Ríos Zambudio A, Illana Moreno J, Piñero Madrona A, Parrilla Paricio P. Miositis osificante aguda. Rev Clin Esp. 2001;201:349-51. 